\title{
Cirurgia reconstrutiva de lábio inferior com recuperação estético-funcional. Relato de dois casos
}

\author{
A.C.N. Nassif Filho, J .R. Shibuio, R.g. Tarlé, J . Arnoud, J .E.G. Maestri
}

Serviço de Otorrinolaringol ogia, Serviço de Dermatologia, Ambulatório de Cirurgia Dermato-Facial da Santa Casa de Misericórdia de Curitiba, Curitiba, PR.

\begin{abstract}
RESUMO - Este artigo relata dois casos de pacientes com carcinoma espinocelular extenso em lábio inferior, submetidos a cirurgia reconstrutiva, utilizando o retalho de avançamento lateral com reconstrução do vermelhão labial.

Objetivo do trabalho: descrição da técnica de reconstrução com retal ho de avançamento lateral, levando-se em consideração a recuperação não somente funcional, mas também estética do paciente.
\end{abstract}

\section{INTRODUÇÃO}

O câncer de lábio é a lesão maligna mais freqüente da cavidade oral, constituindo $15 \%$ dos cânceres da cavidade oral. O câncer de lábio inferior é vinte vezes mais prevalente que o câncer de lábio superior ${ }^{1}$.

A incidência de metástase regional ou a distância varia de $11 \%^{2}$ a $18 \%^{3}$, segundo al guns autores.

As lesões maiores que $2 \mathrm{~cm}$, lesões pouco diferenciadas ao exame anatomopatológico, lesões de comissura ou lábio superior, presença de metástases em gânglio linfático e invasão perineural são de pior prognóstico ${ }^{1}$.

Os lábios são constituídos, basicamente, de pele, músculos e mucosa.

Os músculos são compostos, principalmente, de músculos estriados (músculo orbicular da boca), que são responsáveis pelo movimento dos lábios.

O "vermilion" - vermelhão do lábio - é zona de transi ção entre pel e glabra e a membrana mucosa, encontrada somente em humanos ${ }^{1}$.

A epiderme é característica, com proeminente extrato lúcido e fina camada córnea. A derme papilar é rica em vasos capilares, o que dá cor vermelha dos lábios. Não contém cabelos ou glândulas sudoríparas, com poucas glândulas sebáceas.

\section{DESCRIÇÃO DOS CASOS}

Este trabalho consiste na apresentação de dois pacientes com lesões extensas de carcinoma espinocelular em lábio inferior, atendidos no ambulatório de Cirurgia Dermato-Facial da Santa Casa de
É também sugerida pelos autores uma classificação propondo as principais localizações do carcinoma espinocelular de lábio, a qual permite uma melhor definição quanto à técnica cirúrgica a ser uti lizada em cada caso, dependendo da localização e acometimento ou não da comissura labial.

UNITERMOS: Cirurgia reconstrutiva de lábio inferior. Carcinoma espinocelular. Recuperação estético-funcional.

Curitiba, submetidos à biópsia incisional e exame anatomopatológico para confirmação diagnóstica.

Caso I - Paciente F.V.S., 38 anos, masculino, fumante, tomador de chimarrão, apresentando lesão importante ocupando $50 \%$ do lábio inferior, porém, com a margem cirúrgica de segurança, não acometia comissura labial esquerda. Foi corrigido pequeno defeito estético em lábio superior, em nível ambulatorial, uma semana após a cirurgia principal.

Caso 2 - Paciente L.S., 70 anos, masculino, fumante, apresentando lesão extensa e infiltrante acometendo mais de $70 \%$ do lábi o inferior, e também com a margem cirúrgica de segurança, a lesão não acometia comissura labial direita. A diferença é que o defei to estético que normalmente ocorre no lábio superior foi corrigido no mesmo tempo cirúrgico.

\section{TÉ CNICA CIRÚRGICA}

Os pacientes foram operados, um sob anestesia local assistida e, outro, sob anestesia geral, de acordo com as necessidades e indicações de cada um. As lesões foram demarcadas com margens de segurança nas quais delimitamos um retângulo que se estende lateralmente à comissura labial não comprometida e próxima à lesão. $\mathrm{Na}$ margem inferior do retalho incisamos pele, músculo e mucosa. Já na margem superior, incisamos pele, músculo, e deixamos a mucosa para ser incisada em um plano mais superior, sobrando, assim, tecido suficiente para a reconstrução do novo vermel hão labial. 

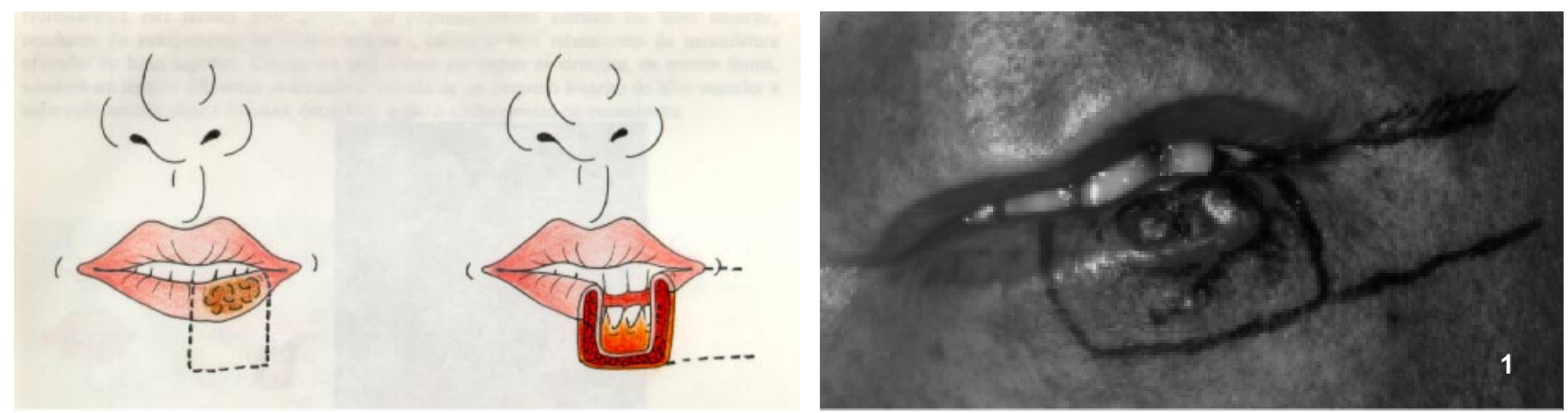

Fig. 1 e foto 1 - Demarcação da lesão com margem de segurança e avançamento lateral de retalho, incisando, inferiormente, pele, músculo e mucosa e, superiormente, pel e, múscul o e deixando sobra na mucosa para a confecção de vermel hão labial.

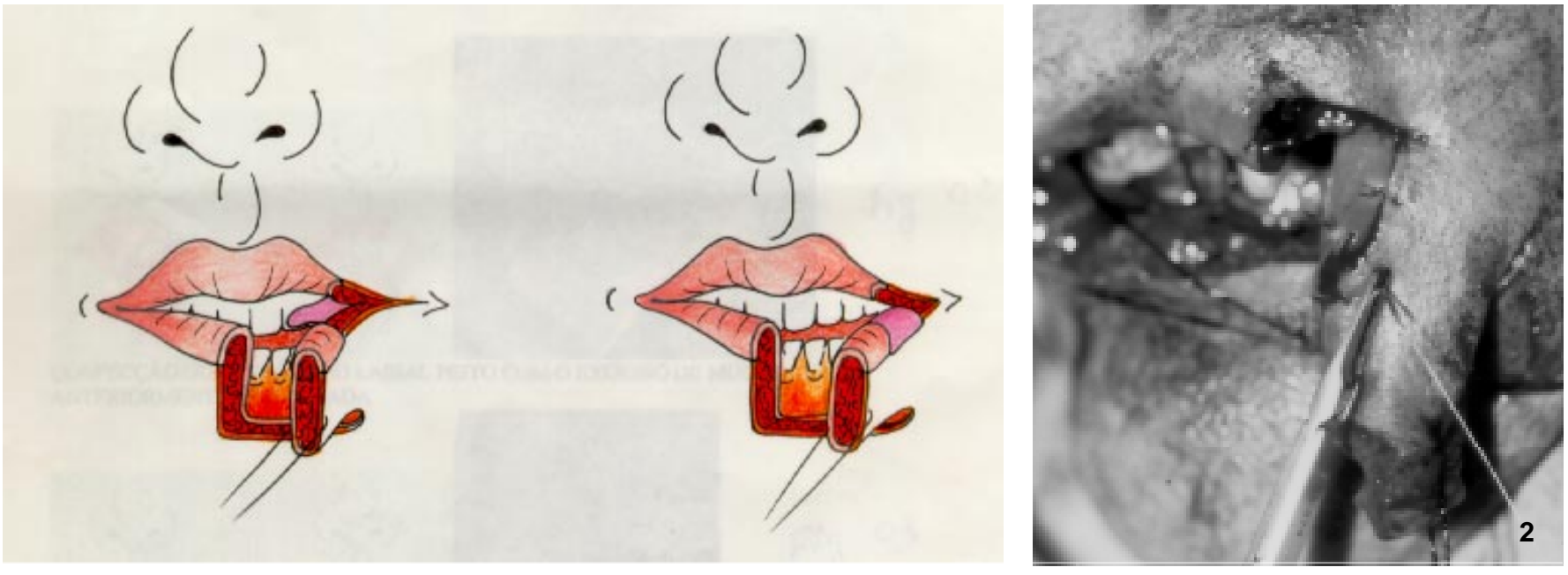

Fig. 2 e foto 2 - Confecção do vermelhão labial feita com o excesso de mucosa jugal anteriormente preservada.
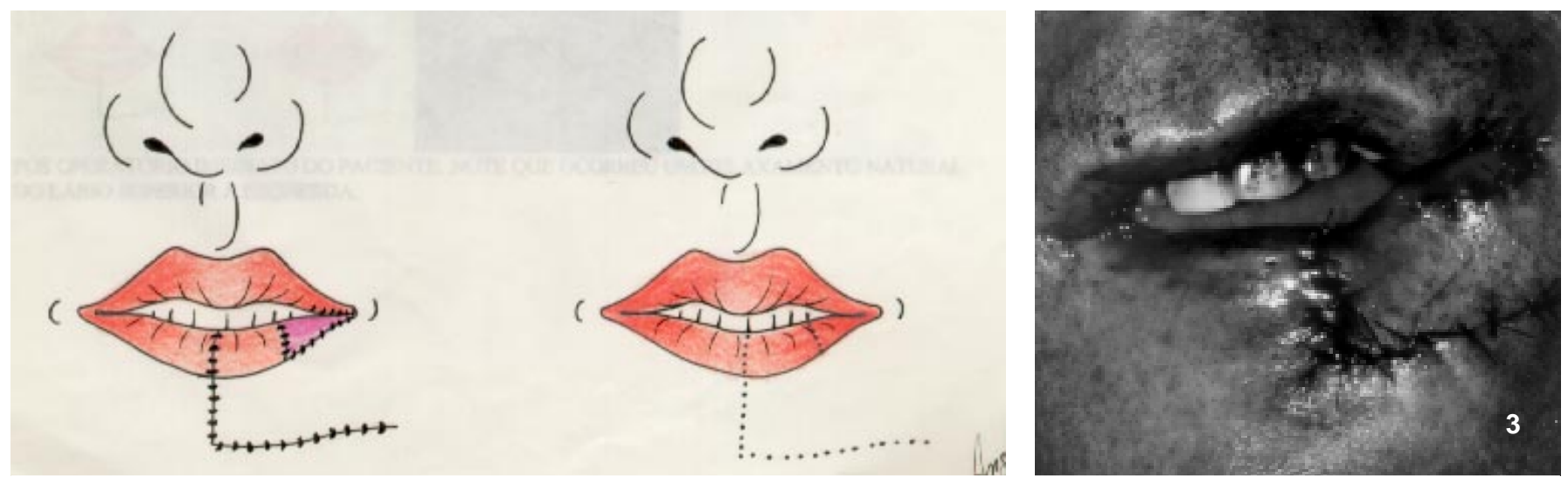

Fig. 3 e foto 3 - Pós-operatório imediato do paciente. Pela foto, nota-se que ocorreu um relaxamento natural do lábio superior à esquerda.

O vermel hão é suturado com vicryl 6.0. Realizamos a sutura do retalho em três planos (mucosa, músculo e pele), sendo suturadas, a mucosa e músculo, com vicryl 4.0, e a pele, com mononylon 6.0.

Normalmente, essa técnica pode resultar em pequeno defeito estético em lábio superior, resultante do avançamento do retal ho inferior, causan- do leve relaxamento da musculatura orbicular do lábio superior. Corrigimos esse defeito, em ambas as cirurgias, da mesma forma, somente em tempos diferentes, realizando a retirada de um pequeno losango de lábio superior e suturando em três planos distintos, suprimindo, então, o afrouxamento da musculatura. 

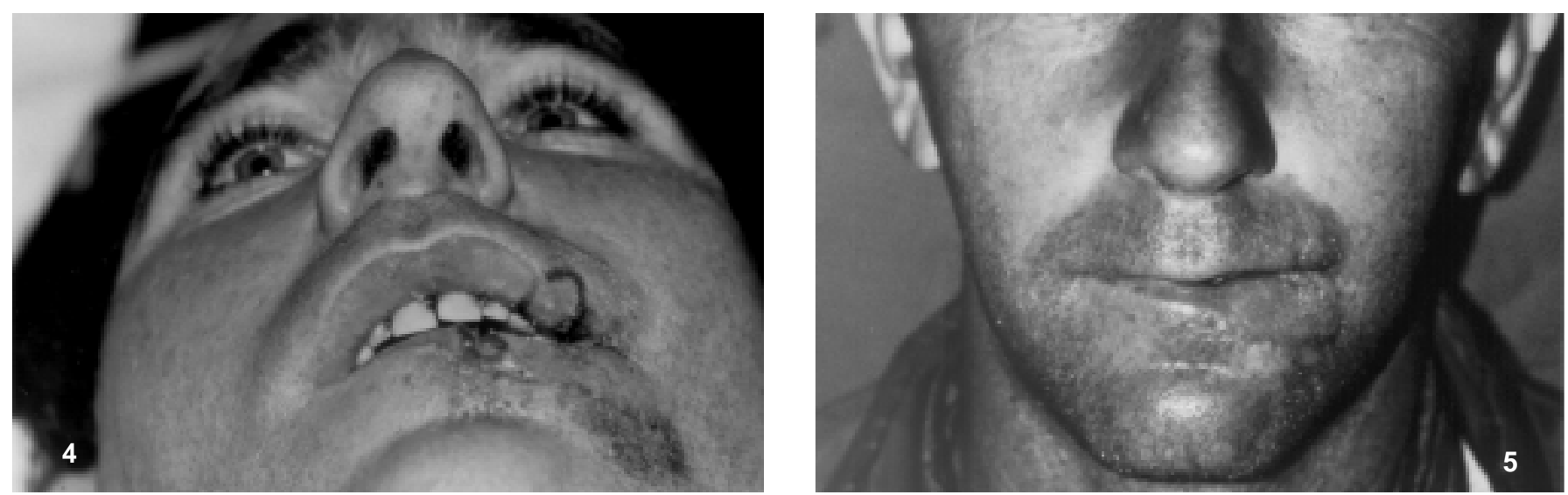

Fotos 4 e 5 - À esquerda, correção do defeito estético de lábio superior uma semana após a cirurgia; e à dir eita, pósoperatório após trinta dias.
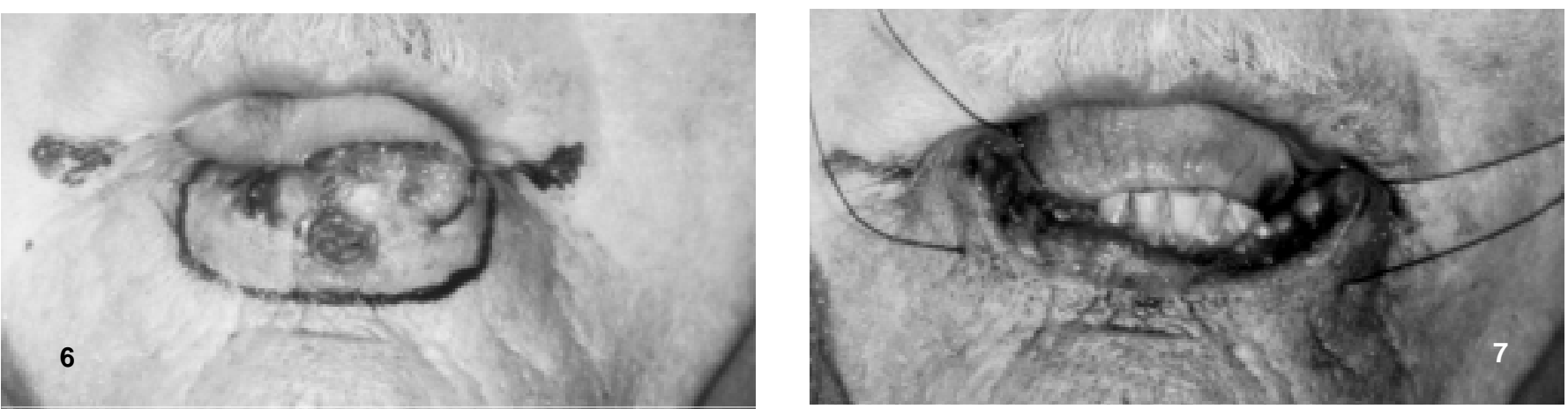

F otos 6 e 7 - Caso 2. Demarcação da lesão e retirada com margem cirúrgica.
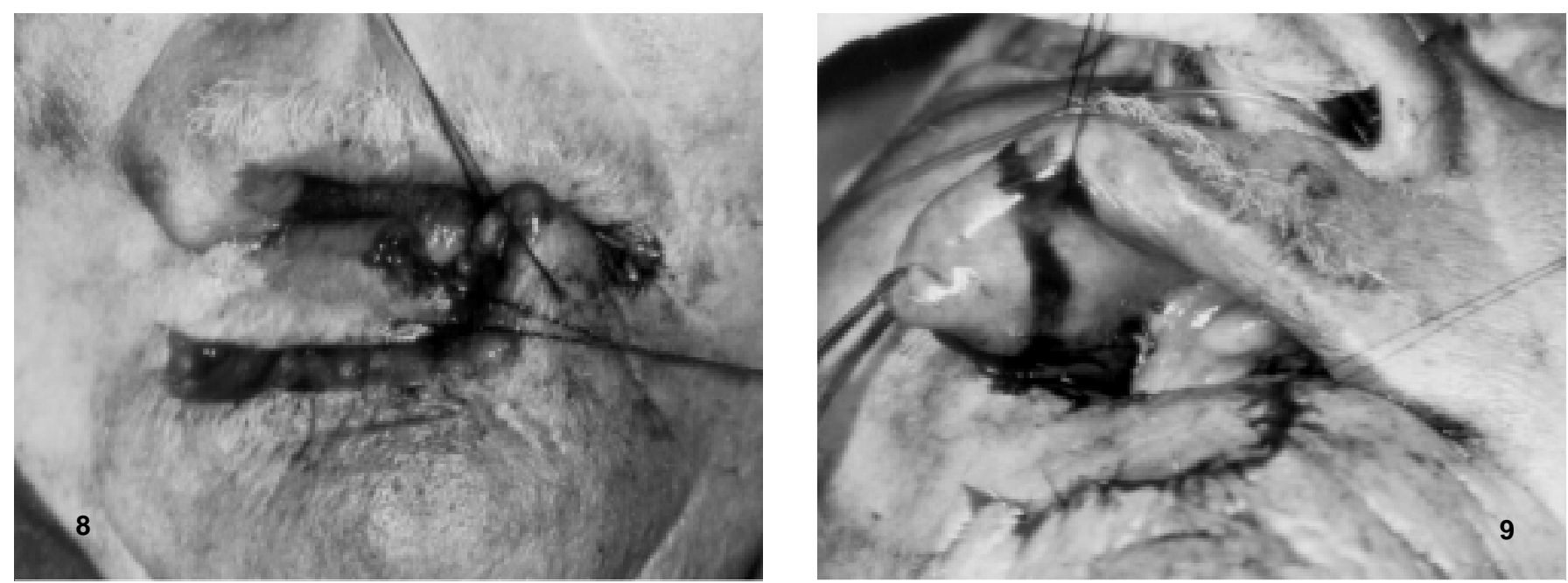

Fotos 8 e 9 - Caso 2. Avançamento lateral deretalho musculocutâneo. À direita, corrigi do o defeito estético delábi o superi or no mesmo tempo cirúrgi co retirando-se parte de mucosa jugal, acabando-se, assim, com o afrouxamento do lábio superior.

\section{DISCUSSÃo}

É importante dizer que, dentre os tumores labiais, a excisão e fechamento primário são apenas aplicados àquel es tumores em que a margem cirúrgi ca não ultrapassa $1 / 3$ do lábio retirado 4 .

Achamos que esta técnica é superior a outras descritas, como, por exemplo, a de Abbe Estlander flap, que consiste na rotação de retalho de lábio superior restaurando o defeito do lábio inferior, com resultados pobres não somente funcional mas, também, estético, com riscos de necrose, tendo, também, a necessidade de ser realizada em dois ou três tempos cirúrgicos. 


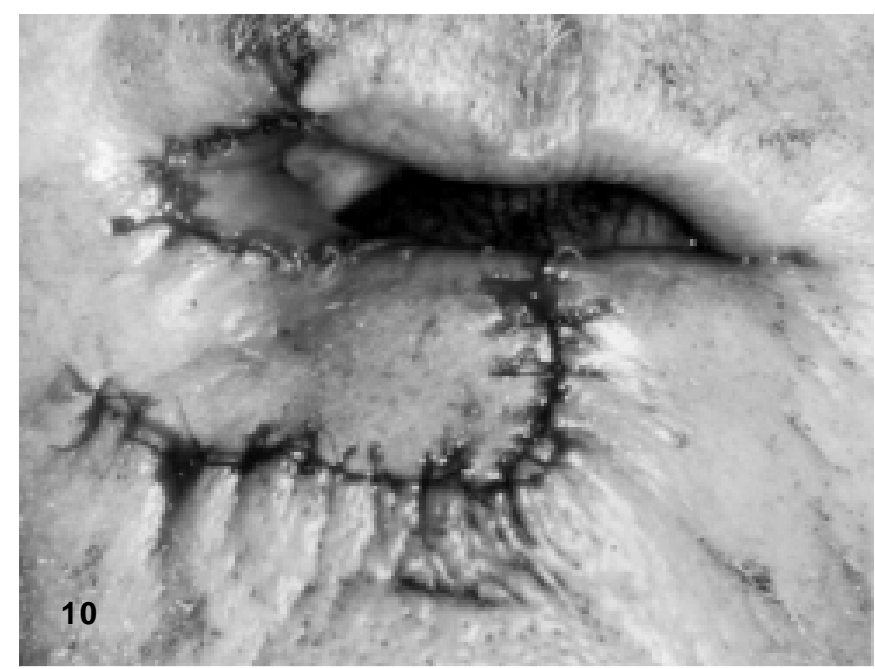

Foto 10 - Caso 2. Pós-operatório imediato.

\begin{tabular}{|ccc|}
\hline \multicolumn{2}{|c|}{ Locais mais freqüentes de lesões (CEC) de lábio } \\
\hline $\begin{array}{c}{ }^{*} \text { Pele } \\
\text { Supralabial } \\
\text { Infralabial } \\
\text { *Vermelhão } \\
\text { Lábio superior }\end{array}$ & Central & \\
& Paramediano & $\begin{array}{l}\text { Margem cirúrgica não atinge } \\
\text { comissura } \\
\text { Atinge comissura }\end{array}$ \\
& Central & Paramediana \\
& Paramediano & $\begin{array}{l}\text { Margem cirúrgica não atinge } \\
\text { comissura } \\
\text { Atinge comissura }\end{array}$ \\
\hline
\end{tabular}

Outro detalhe a salientar é que a classificação que mostramos acima pode beneficiar o cirurgião, ajudando-o a sel ecionar a técnica mais apropriada a ser utilizada.

Normalmente, nas lesões paramedianas de vermelhão que não acometem a comissura, tanto de lábio inferior como superior, optamos pelo retal ho de avançamento lateral por entendermos ser mais eficaz. A aplicação desta técnica em lábio superior tem pequenas diferenças, que já foram descritas 5 .

J á nas lesões de lábio inferior paramedianas, em que se acomete comissura labial, uma técnica que possui bom resultado cirúrgico é a de KuntZymanoski, que consiste na rotação de pele, músculo e mucosa ao nível de sulco nasogeniano, corrigindo o defeito de lábi o inferior, técnica esta que poderá ser mostrada em outra oportunidade.

É importante salientar que em todas as cirurgias reconstrutivas de lábi o que realizamos temos por intenção, primeiramente, retirar a lesão com

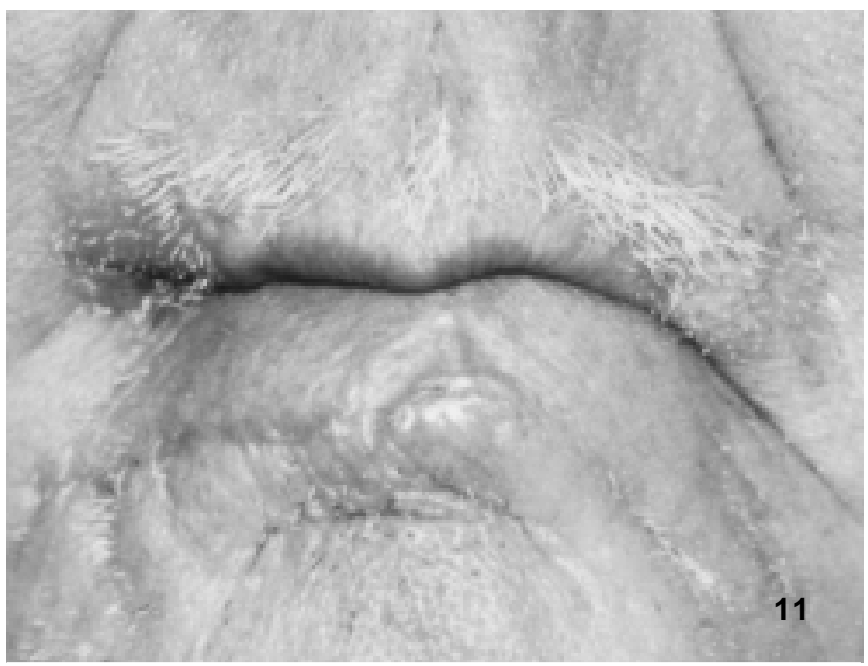

Foto 11 - Caso 2. Pós-operatório após trinta dias.

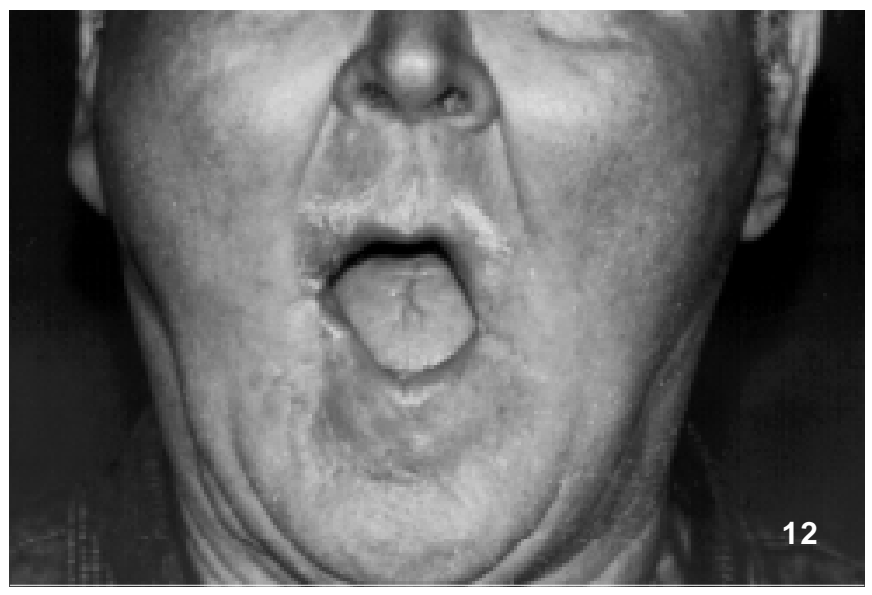

F oto 12 - Caso 2. Pós-operatório após trinta dias.

margem de segurança, mas consideramos, também, de extrema importância a recuperação estético-funcional desse paciente, permitindo-Ihe seu pronto retorno ao convívio social.

\section{CONCLUSÃO}

Este é mais um trabalho de cirurgia labial em que enfocamos a recuperação não somente funcional, mas também estética dos pacientes. Existe uma variedade de técnicas a serem aplicadas a cada caso, mas entendemos que umas possuem mel hores resultados que outras. É importante aplicar técnicas em que podemos resolver os casos em apenas uma ou duas intervenções cirúrgicas, evitando-se, assim, riscos de resultados estético- funcionais pobres.

$\mathrm{N}$ ão esquecer de reavaliar esses pacientes com rigoroso seguimento nos primeiros dois anos da terapia, para avaliação de recidivas locais ou até metástase em linfonodos ${ }^{6}$. 


\section{SUMMARY}

Reconstructive surgery of the lower lip with esthetic-functional recovery. Report of two cases

Two cases of patients with large squamous cell carcinoma in the lower lip, that were submitted to the reconstructive surgery, using technique of lateral progress with reconstruction of the red lip, always tends the concern of the recovery not only functional as well as aesthetic of these pacients ones, are reported.

A classification is given suggesting the main locations of the squamous cell carcinoma of thelip, allowing better definition with relationship to the surgical technique to be used in each case, depending on the location and involvement or not of the lip comissure. [Rev Ass Med Brasil 44(3): 256-60.]
KEY WORDS: Reconstructive surgery of the lower lip. Squamous cell carcinoma. Esthetic-functional recovery.

\section{REFERÊNCIAS BIBLIOGRÁFICAS}

1. Champion R, Burton J, Ebling F. Rook's textbook of Dermatology. $5^{\text {th }}$ ed. Oxford, Blackwell Scientific Publications, 1992.

2. Teichgraeber J F, Larson LD. Some oncologic considerations in the treatment of lip cancer. Otolaryngol Head Neck Surg 1988; 1: 589-92.

3. Gregor GI, Davis NL, Hay J H. I mpact of cervical lymph node metastasis from squamous cell cancer of the lip. Am J Surg 1992; 163: 469-71.

4. Pitkanen J , Lathi A, Sundell B. Carcinoma of thelip. Scand J Plast Recontr Surg 1985; 19: 289-94.

5. Nassif Filho ACN, Tarlé RG, Oliveira AD. Cirurgia reconstrutiva de lábio superior com recuperação estético-funcional. Rev Ass Med Brasil 1996; 42(3): 151-4.

6. Gregor GI, Davis NL, Hay J H. I mpact of cervical lymph node metastases from squamous cell cancer of the lip. Am J Surg 1992; 163: 469-71. 